\title{
Relation of air mass history to nucleation events in Po Valley, Italy, using back trajectories analysis
}

\author{
L. Sogacheva ${ }^{1}$, A. Hamed ${ }^{2}$, M. C. Facchini ${ }^{3}$, M. Kulmala ${ }^{1}$, and A. Laaksonen ${ }^{2,4}$ \\ ${ }^{1}$ Division of Atmospheric Sciences, Department of Physical Sciences, P.O. Box 64, 00014 University of Helsinki, Finland \\ ${ }^{2}$ Department of Physics, University of Kuopio, P.O.Box 1627, 70211 Kuopio, Finland \\ ${ }^{3}$ Istituto di Scienze dell'Atmosfera e del Clima - CNR, Italy Via Gobetti 101, 40129 Bologna, Italy \\ ${ }^{4}$ Finnish Meteorological Institute, Erik Palménin aukio, FI-00560 Helsinki, Finland
}

Received: 29 September 2006 - Published in Atmos. Chem. Phys. Discuss.: 13 November 2006

Revised: 5 February 2007 - Accepted: 9 February 2007 - Published: 15 February 2007

\begin{abstract}
In this paper, we study the transport of air masses to San Pietro Capofiume (SPC) in Po Valley, Italy, by means of back trajectories analysis. Our main aim is to investigate whether air masses originate over different regions on nucleation event days and on nonevent days, during three years when nucleation events have been continuously recorded at SPC. The results indicate that nucleation events occur frequently in air masses arriving from Central Europe, whereas event frequency is much lower in the air transported from southern directions and from the Atlantic Ocean. We also analyzed the behaviour of meteorological parameters during $96 \mathrm{~h}$ transport to SPC, and found that, on average, event trajectories undergo stronger subsidence during the last $12 \mathrm{~h}$ before the arrival at SPC than nonevent trajectories. This causes a reversal in the temperature and relative humidity $(\mathrm{RH})$ differences between event and nonevent trajectories: between 96 and $12 \mathrm{~h}$ back time, temperature is lower and $\mathrm{RH}$ is higher for event than nonevent trajectories and between 12 and $0 \mathrm{~h}$ vice versa. Boundary layer mixing is stronger along the event trajectories compared to nonevent trajectories. The absolute humidity (AH) is similar for the event and nonevent trajectories between about $96 \mathrm{~h}$ and about $60 \mathrm{~h}$ back time, but after that, the event trajectories $\mathrm{AH}$ becomes lower due to stronger rain. We also studied transport of $\mathrm{SO}_{2}$ to $\mathrm{SPC}$, and conclude that although sources in Po Valley most probably dominate the measured concentrations, certain Central and Eastern European sources also make a substantial contribution.
\end{abstract}

\section{Introduction}

New particle formation in atmosphere draws considerable attention (Kulmala et al., 2004) due to the possible climate and health effects of aerosols. Although widely studied, aerosol

Correspondence to: L. Sogacheva

(larisa.sogacheva@helsinki.fi) characterization is still hindered by our poor understanding of the formation processes of secondary aerosols, which are formed via gas phase condensation, and contribute to the relative abundance of primary aerosols formed via mechanical or combustion processes. Sulphur, together with many nitrogen and carbon compounds, undergo gas-to-particle transition, and they are ultimately removed from the atmosphere via aerosol deposition processes. Therefore, the lifetimes and concentrations of these species are defined by aerosol dynamics. Better understanding of new particle formation will therefore contribute also to our comprehension of atmospheric chemistry in general.

The causes of air pollution and particle formation episodes are complex and depend on various factors including emissions of precursors, pre-existing aerosols, meteorological parameters (in particular solar radiation, temperature and relative humidity), topography, and photo-chemical processes (see, e.g. Kulmala et al., 2001, 2003). Air masses of different origin poses different meteorological and chemical characteristics, and therefore, from the Eulerian viewpoint, the probability of occurrence of new particle formation events at a given location and time depends not only on local emissions, but on airflows and long range transport (Sogacheva et al., 2005a).

The Po Valley in Northern Italy, which is characterized by high industrial, urban and traffic emissions, has the country's worst problems with air pollution, especially because the weather conditions, typical for that area, have a tendency to trap the pollutants, rather than to disperse them. This has an extremely negative impact on air quality. New particle formation is suppressed by high concentration of pre-existing particles, because of increased condensation sink for vapours that would otherwise nucleate to form new particles. It was therefore rather surprising to discover that intensive nucleation events actually occur frequently in the Po Valley (Laaksonen et al., 2005; Hamed et al., 2007). Here we investigate, by means of back trajectories analysis, how new particle

Published by Copernicus GmbH on behalf of the European Geosciences Union. 


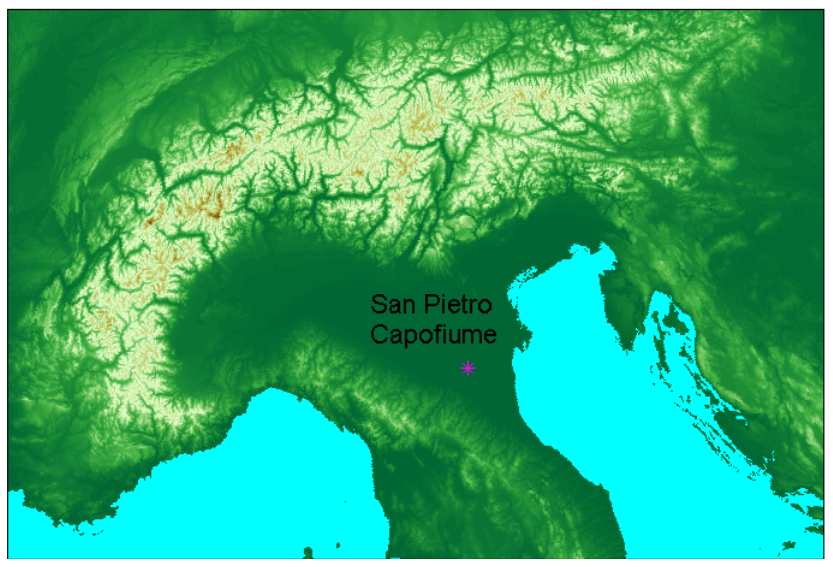

Fig. 1. Po Valley, San Pietro Capofiume (SPC) measurement station.

formation is affected by the transport of the air masses of different origin.

Long-range transport of photochemical gaseous, air pollutants and particulate matter has been studied extensively in Europe during the last decades under the framework of several national and international efforts. Many experimental research programs, e.g. EUROTRAC-2 (Kruger et al., 2000), PIPAPO (Steinbacher et al., 2005a, b), MINATROC (Putaud et al., 2004; Van Dingenen et al., 2005), free Tropospheric campaign (Balkanski et al., 2003) have been carried out over the Alps, the Apennines and the Po Basin area. Several manuscripts have been published about the pollutants at high elevation Alpine sites. Pichlmayer et al. (1998) combined isotope analysis with back trajectories and found out the pre-industrial and modern origin for nitrates and sulfates, respectively. Siebert et al. (1998) using trajectory analysis concluded that the Po Valley contribute to about $15 \%$ of pollutants at Sonnblick (3106 m a.s.l.) and Jungfraujoch $(3579 \mathrm{~m}$ a.s.l.) in summer and much less in winter. Bertò et al. (2004) using back trajectories estimated the backtracking water vapour contribution to a precipitation event over Trentino, Alpine target area, and concluded that most of precipitation seems to be produced by air parcel residing over the Mediterranean Sea and the North African coast. Bonasoni et al. (2000) using trajectory statistics revealed that in warm season the highest background ozone concentration were related to air mass coming from northerly and easterly latitudes, while the highest ozone values for nonbackground conditions originated in Northern Italy and central Europe. Wotawa et al. (2000) estimated ozone formation along the trajectories crossing the Po Basin using measurements in the Alps and the Apennines and 3-D backward trajectories. They concluded that both emissions from nearby areas and the European emission transported over the continent have to be considered. Steinbacher et al. (2005a, b) presented the results of the measurements of aromatic com- pounds, as well bimodal isoprene cycles during three measurement campaigns. The meteorological conditions causing air pollution episodes in the central Po Valley have been investigated by Finardi and Pellegrini (2004). The role of anticyclonic weather type have been emphasized along with weak winds and calms.

The aim of the present paper is to find out if there is any preferable direction for air mass transport before the particle formation starts at SPC and what meteorological conditions along the air parcel trajectory dominate for cases when the formation of new particle occurs at SPC. We also investigate the transport directions for event and nonevent days against the $\mathrm{SO}_{2}$ sources over the Europe, using EMEP data, and calculated the $\mathrm{SO}_{2}$ potential emission sources.

\section{Site description}

The San Pietro Capofiume (SPC) measurement station $\left(44^{\circ} 39^{\prime} \mathrm{N}, 11^{\circ} 37^{\prime} \mathrm{E}\right)$ is located at $11 \mathrm{~m}$ a.s.l., about $30 \mathrm{~km}$ northeast from the city of Bologna, in Po Valley (Fig. 1). The Po Valley lies between the Alps to the north and the Apennines Mountains to the south-south-west. The Alp mountain chain, reaching elevations of well over $4000 \mathrm{~m}$, extends from the west to east, acting as a protection barrier against the cold wind blowing from the north, giving rise to a climatic pattern different from that of Central Europe.

The Po Valley axis is prevalently oriented west-east: this maximizes the shading effect of the mountains on the bottom of the valley, enhancing differences in radiation, flow and turbulence over mountain slopes. The atmospheric circulation in the Po Valley is characterized by the strong modification of air flow due to high mountains that surround the valley on three sides. The dynamic effects of mountains also have a major impact on regional and local airflow patterns that impact the climate of adjacent regions. The surface properties and the presence of mountains and sea in the area lead to the development of strong sea breezes, upslope winds, or the combination of the two, depending on mountain/coast orientation. The complex airflow configuration in the valley affects significantly the temporal and spatial variation of pollutant concentrations.

The local atmospheric circulation features, dominated by calm and weak winds, often favour the development of critical pollution episodes (Finardi and Pellegrini, 2004).

Po Valley is densely populated, highly industrialized and known to have a relatively high level of anthropogenic pollution. High levels of pollutants are reported for the Po Valley region ("Provincia Bologna, Pianificazionee gestione della qualità dell'aria nella provincia di Bologna, parte prima: Valutazione della qualita' dell'aria, 2003", available at http: //www.provincia.bologna.it/ambiente/). Mineral dust transportation episodes during the air mass transport from the North African source region (Ansmann et al., 2003; Bonasoni et al., 2004) often happen, increasing significantly the 
particle concentration. Another natural particulate source, sea spray, is involved in heterogeneous reactions with anthropogenic gaseous pollutants and may modify the processes leading to gas to particulate conversion (O'Dowd et al., 1997, 2004).

\section{Measurements of particle size distribution, gas con- centrations and meteorological parameters}

The particle size distribution measurements at SPC have been ongoing since March 2002 and cover the period of three years up to March 2005. The measurements at $3 \mathrm{~m}$ height were carried out using a twin Differential Mobility Particle Sizer (DMPS) system: the first DMPS measures particle size distributions between 3-20 nm and the second one between 15-600 nm (Hamed et al., 2007). In addition to particle size measurements, several gas and meteorological parameters are being measured at SPC (at $3.5 \mathrm{~m}$ height and $1.5 \mathrm{~m}$ height, respectively), including $\mathrm{SO}_{2}, \mathrm{NO}, \mathrm{NO}_{2}, \mathrm{NO}_{\mathrm{x}}, \mathrm{O}_{3}$, temperature, relative humidity, wind direction, wind speed, global radiation, precipitation, and atmospheric pressure (Hamed et al., 2007).

\section{Classification of the new particle formation events}

The processes of particle formation and growth depend on a combination of different factors, causing the intensity nucleation events to be variable. When the formation of new aerosol particles starts at (or near) the lowest measurable particle size (diameter $3 \mathrm{~nm}$ ) and subsequent growth of the newly formed particles is observed for several hours, a day is considered as a nucleation event day. The nucleation event classification used here is based on event clarity, i.e. the number concentrations of the freshly formed particles, and their formation and growth rates (for more details see Hamed et al., 2007). The nucleation event classes 1,2 and 3 refer to strong, intermediate, and weak events, respectively. To minimize the uncertainty of the classification subjectivity, the weak class 3 events were excluded from some calculations, as will be detailed below.

The days with no particle formation are classified as nonevent days. The days which do not fulfill the criteria to be classified as the event and nonevent days were combined into one group, called undefined days. Table 1 summarizes the numbers of nucleation event days (class 1,2 and 3 events) undefined and nonevent days, as well as the fraction (\%) of the different types of days.

\section{Back trajectories analysis}

To analyze the source and transport pathways of the air masses arriving at SPC, the back trajectories analysis was done for the period of measurements using the HYSPLIT_4
Table 1. Number of nucleation event days (class 1, 2 and 3), undefined and nonevent days, as well as the fraction $(\%)$ of the different types of days.

\begin{tabular}{lll}
\hline & Number of days & $\begin{array}{l}\text { \% from total number } \\
\text { of operational days }\end{array}$ \\
\hline event, class 1 & 45 & 5.9 \\
event, class 2 & 91 & 11.8 \\
event, class 3 & 143 & 18.6 \\
undefined days & 236 & 30.7 \\
nonevent & 254 & 33.0 \\
Total & 769 & 100.0 \\
\hline
\end{tabular}

model, developed by NOAA/ARL (Draxler and Hess, 1998). HYSPLIT_4 is a single particle lagrangian trajectory dispersion model. The model runs were made using Global FNL meteorological archive with a spatial resolution of $191 \times 191 \mathrm{~km}$. The back trajectories were calculated typically $96 \mathrm{~h}$ backwards in time at $100-\mathrm{m}$ arrival height above ground level between 08:00 and 20:00 UTC with 2-h resolution. However, in some calculations we used only the trajectories that arrived at 10:00 UTC, i.e. around the nucleation event start time (Hamed et al., 2007). Some trajectories were missing or shorter than $96 \mathrm{~h}$ in duration, since the FNL archive data has some gaps when input meteorological data are not available.

Current literature suggest that the error accompanying HYSPLIT-generated trajectories can be estimated to be anywhere from $15 \%$ to $30 \%$ of the travel distance (Stohl, 1998; Draxler and Hess, 2004). The uncertainty increases with the length of transport, and the horizontal uncertainty four days before the arrival at SPC can reach several hundreds of kilometers. However, individual trajectories may have much larger errors, especially since the model topography and the real topography do not match exactly. Another potential source of uncertainty is due to the regions of near-zero wind velocity which were encountered in many of trajectories (Stohl et al., 1995). For the purposes of the present paper, the accuracy of back trajectory calculations is sufficient to reveal the differences in nucleation event frequencies for air masses of different types and history.

Vertical position of the air parcel, mixed layer depth, as well the air parcel properties along the trajectory such as relative humidity, ambient temperature, and rain intensity were estimated by HYSPLIT trajectory model using the global FNL archive (http:www.arl.noaa.gov/ss/transport/ archives.html). The 6-hourly FNL archive data are generated by the NCEP GDAS (National Centers for Environmental Prediction Global Data Assimilation System) wind field reanalysis. GDAS uses the spectral medium range forecast (MRF) model for the prognoses. The FNL database contains basic fields such as the u- and v-wind components, 

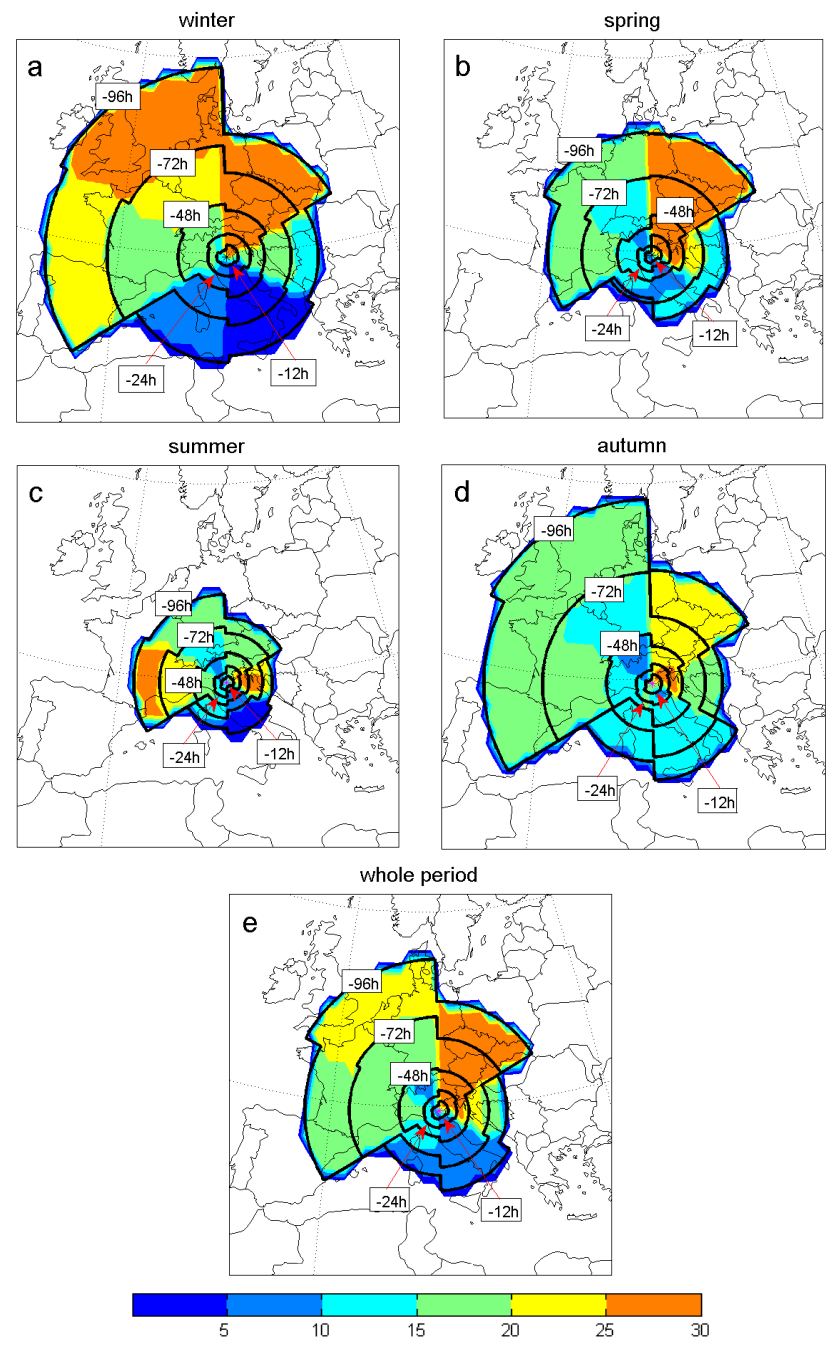

Fig. 2. Frequency (\%, color) of the location of an air parcel in different direction sectors between the reference back time steps (contour line for $-12 \mathrm{~h},-24 \mathrm{~h},-48 \mathrm{~h},-72 \mathrm{~h},-96 \mathrm{~h})$ for the different seasons $((\mathbf{a})-$ winter, (b) - spring, (c) - summer, and (d) - autumn) and for the whole period of measurements (e).

temperature, and humidity at 13 vertical levels, from the surface up to $20 \mathrm{hPa}$. For estimation of the water content, which is an essential property affecting aerosol particle condensation and deposition processes (e.g. Vesala et al., 1997), we calculated the absolute humidity for each back point of the trajectory. We also calculated the vertical and horizontal speed of air parcel to estimate if the air masses transfer rate varies for different days classified according to nucleation event clarity.

\section{Air mass transport direction}

To estimate the air mass main transport direction to SPC for different seasons and the whole year we calculated the frequency of the location of the reference $(12,24,48,76$, and
$96 \mathrm{~h}$ ) back points in $60^{\circ}$ degree sectors: north-east (NE), east (E), south-east (SE), south-west (SW), west (W), and northwest $(\mathrm{NW})$. Also for each sector we calculated the mean travelling distance between reference back points to estimate the air mass travelling distance at different path sections.

At SPC the prevailing $\mathrm{W}$ to NE atmospheric flows are clearly seen (Fig. 2). During winter the Westerlies are associated with the subpolar low pressure zone which is located over the ocean just to the south of Greenland and the Aleutian Islands. The depression activity causes a variety of circulation patterns over South Europe. Some of these patterns, generally accompanied by vertical atmospheric stability with to temperature inversions and poor vertical mixing, are responsible for accumulation of air pollutants, while others, as the northerly flow, do not favour high pollutant concentrations. The Western Mediterranean Basin is better ventilated due to 
frequent passages of travelling low pressure zones and their frontal systems. However, as soon as anticyclonic conditions develop, air pollution can be trapped within industrialized valleys or in large, but confined air sheds (Millan, 2002).

More than $40 \%$ of the air masses arriving at SPC in winter (Fig. 2a) have been originated or passed over the Atlantic and Central Europe. The air mass transport distance is the highest in that direction compared to other sectors. The velocity of an air parcel decreases towards arrival point due to the increasing influence of the surface roughness. The fraction of the air flows originating from over the Western Europe was about $20-25 \%$. The frequency of the trajectories coming from over Russia and Central Europe was much lower and the travelled distance is on average much shorter than one for the air masses coming from the NW. However, baric systems and consequently the transport directions at each specific moment can be essentially different from those estimated by the averaging.

In early spring, the high pressure conditions become more favourable, forcing the low pressure belt to the north. The amount of global radiation at SPC increases considerably compared to winter period (Hamed et al., 2007). Sahara brings forth dry hot air that expands across the Mediterranean Sea northwards to the Alps and covers Italy. However the frequencies of the SE to SW transport directions (Fig. 2b) remains low (up to 15\%). The travel distance decreases in all directions but the NE, which remains to be the prevailing direction in air mass transport. More than 25\% of trajectories arrive from that direction. Originating in the Eurasian landmass, the predominant air mass contains little moisture, and as it passes from cooler to hotter regions the water carried along is evaporated more rapidly than local cloud-forming eddies can condense it.

Subtropical high pressure zone dominates in summer.In anticyclonic circulation the subsiding air creates stable atmospheric conditions, suppressing cloud development and precipitation. The cloudless conditions commonly experienced during both the daytime and the night cause significant heat gain and loss during the day. As a result the climate experiences a large daily temperature range during summer. The travel distance of air mass is the shortest in summer (Fig. 2c) compared to other seasons in all the directions. The frequency of the local wind low speed conditions $(<2 \mathrm{~m} / \mathrm{s})$ is significant for that period (Hamed et al., 2007). The influence of the underlying territories to the air mass properties is strongest during that season.

In autumn high pressure belts drift back towards the equator, and the weather becomes more dominated by the rain-bearing low/pressure depression. The transport distance increases in north-west direction, whereas the distribution of the trajectories in all sectors becomes more uniform (Fig. 2d). However, the west to northeast sectors still have the highest (15\% to $25 \%$ ) frequency.

Thus, during the whole period of measurements (Fig. 2e) the W, NW and NE air mass directions prevail and make up

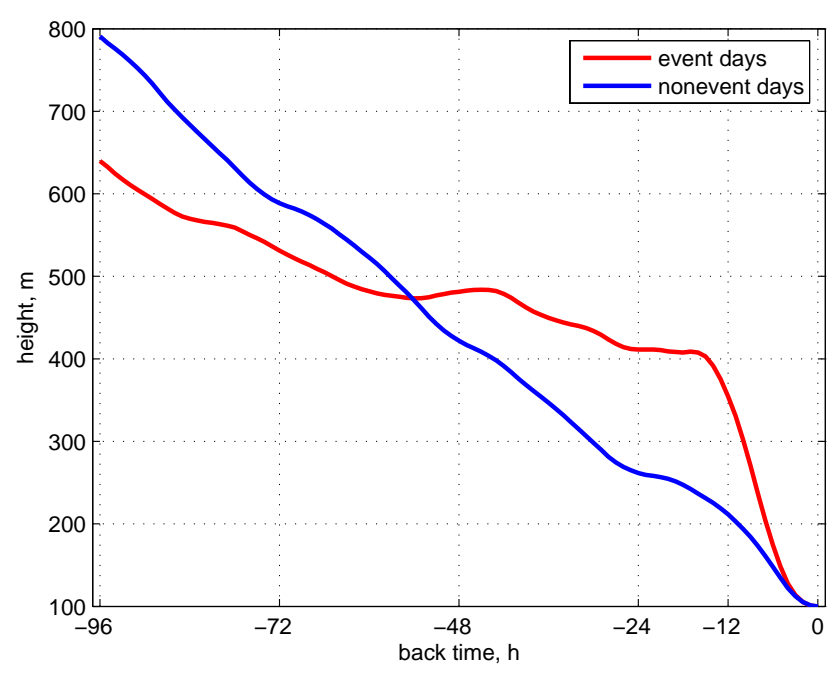

Fig. 3. Air parcel mean vertical height before the arrival at SPC for nucleation event (class 1 and 2) and nonevent days.

from $15 \%$ to over $25 \%$ frequency each. The frequency of SE and SW direction is lower (below 10\%).

\section{Meteorology along the trajectory}

The effect of the meteorological parameters on aerosol particle formation has been widely studied. Nilsson et al. (2001) investigated the effect of continental boundary layer evolution, convection and turbulence on aerosol formation. The influence of meteorological parameters on nucleation events is of interest as well (see, e.g. Boy et al., 2002; Lyubovtseva et al., 2005). Hellmuth (2006) investigated gas-aerosolturbulence interaction in the convective boundary layer and concluded that the observations from the surface layer alone are not consultive to elucidate the origin of newly formed particles. Hyvönen et al. (2005) using data mining technique found that aerosol particle formation events observed in boreal forests are connected with two variables, the condensation sink and relative humidity. Hamed et al. (2007) revealed that the condensation sink values at SPC are lower on event days than on nonevent days. In present studies we aimed to find out the magnitude of the condensation sink in air masses of different origin using back trajectories (for more details see Sogacheva et al., 2005b); however, no significant differences in condensation sink values measured at SPC depending on air mass origin and transport direction have been found (results are not presented).

While meteorological conditions favouring the new particle formation at SPC are relatively well understood (Hamed et al., 2007), the air mass properties at the recipient and along the trajectory for event end nonevent days are poor characterized. However, the identification of the air mass properties favourable for the episodes of new particle formation 

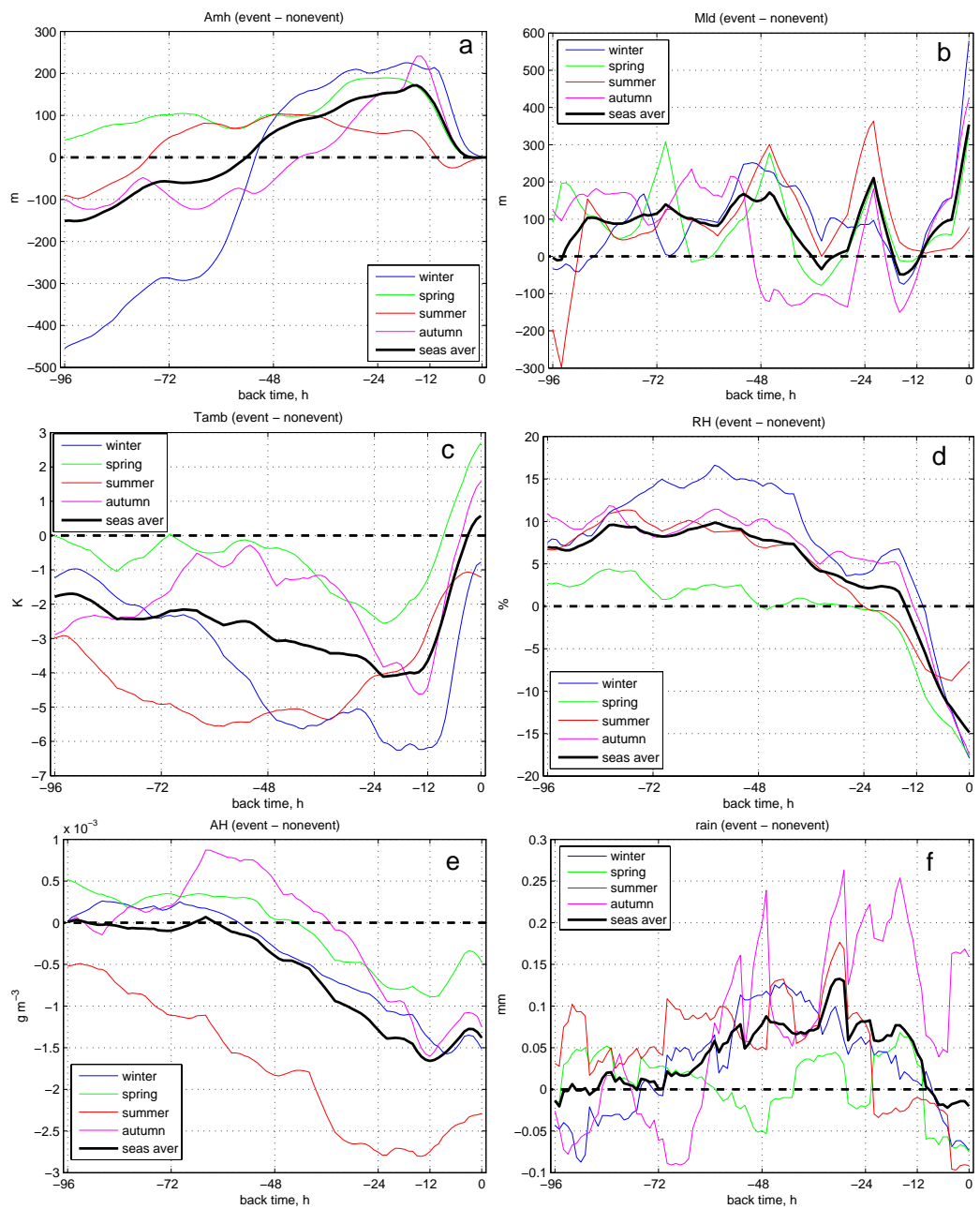

Fig. 4. Difference in meteorological parameters between event and nonevent trajectories for different seasons (blue line - winter, green line spring, red line - summer, magenta line - autumn) and seasonal average (black line). (a) Air mass height, (b) Mixed layer depth, (c) Ambient Temperature, (d) Relative Humidity, (e) Absolute Humidity, (f) Rain along the trajectory.

is important for understanding the processes leading to that phenomenon. The air mass main properties, such as temperature and humidity, established over a particular region of the earth's surface (air mass source region), undergo specific modifications while the air mass moves away from the source region to the recipient. The acquired additional attributes, in turn, depend on properties of the transition region and the duration the air mass spent over that region. The specific character of the transition regions may result in drastic changes in air mass properties even if they were originated over the same region.

However, the vertical distributions of the meteorological parameters also influence the air parcel properties. Stronger compared with nonevent cases subsidence of air parcel during on average last $12 \mathrm{~h}$ before the arrival at the SPC (Fig. 3) foregoes the nucleation particle formation event and clarifies the difference in the behaviour of several meteorological pa- rameters, such as air mass height (Amh), mixed layer depth (Mld), relative humidity (RH), rain (R), absolute humidity $(\mathrm{AH})$, and ambient temperature (Tamb) between event and nonevent days (Fig. 4).

For all the seasons but for spring, the "event" air parcel, arrived at SPC during the event day, starts on average to subside at its point of origin ( $96 \mathrm{~h}$ back before the arrival) from the lower height, compared to "nonevent" air parcel (Fig. 4a). The maximum difference (up to $450 \mathrm{~m}$ ) between the event and nonevent air parcel heights at point of origin is observed in winter. However, event parcels have a lower vertical velocity compared to nonevent parcels up to approximately $12 \mathrm{~h}$ before the arrival, and, therefore, the average Amh difference reverses at some point (between $77 \mathrm{~h}$ back point in summer and $42 \mathrm{~h}$ back point in autumn on average) and event parcels travel further to SPC higher than nonevent parcels. About $12 \mathrm{~h}$ before the arrival, a strong subsidence of the event air 
parcel starts, which may correspond to post-frontal synoptic situation or anticyclone weather type with clear sky conditions, when the temperature vertical gradient is higher. As a consequence, the velocity gradient increases. The subsidence warms the air by compression. Any clouds presented quickly evaporate as the temperature of the air rises above its dew point. For this reason, anticyclones usually bring fine, dry and settled weather, particularly in summer.

The atmosphere boundary layer mixing around noon is stronger along the event compared to nonevent trajectories. The amplitude of the difference in Mld between event and nonevent trajectories becomes higher on the way to recipient except for summer and is about $350 \mathrm{~m}$ at SPC on seasonal average (Fig. 4b). In winter the difference in Mld between event and nonevent days reaches more than $600 \mathrm{~m}$.

Ambient temperature of the air parcel (Fig. 4c) is lower for event trajectories along the whole air parcel path, except for several (up to 10) hours before arrival at SPC. This corresponds well to the strong subsidence of event air parcel during the last $12 \mathrm{~h}$ of its way. On seasonal average, the air mass temperature during event days at the recipient is about $0.5^{\circ}$ higher compared to nonevent air mass temperature. The temperature difference at the recipient reaches a maximum value in spring $\left(2.7^{\circ}\right)$. The highest temperature difference (about $6^{\circ}$ ) between the event and nonevent trajectories on the way to recipient is observed in winter and summer, whereas at the recipient the event air mass is about $1^{\circ}$ colder compared to nonevent air masses in that seasons.

Differences in relative humidity (Fig. 4d) and absolute humidity (Fig. 4e) behave opposite to the ambient temperature difference. As it was mentioned above, strong subsidence of an air parcel together with the temperature increasing makes the air parcel dryer during the event days. $\mathrm{RH}$ is about $5 \%$ to $10 \%$ higher on seasonal average along event trajectories. The difference in RH is smaller (less than 5\%) in spring and a little higher in winter (up to 15\%). Being slightly higher for event trajectories at $96 \mathrm{~h}$ back point, $\mathrm{AH}$ decreases compared to that of nonevent cases at a distance, close to where the difference in rain along the back trajectory between event and nonevent days for different seasons (Fig. 4f) becomes positive. Minor decrease in difference is observed during the last $12 \mathrm{~h}$ before the arrival. However, being related to the absolute temperature as well, $\mathrm{AH}$ is considerably lover along the event trajectory in summer compared to other seasons.

The mean meteorological parameters for event and nonevent days, such as Tamb and RH, calculated by Hysplit_4 model at the recipient show a good agreement with the measurement values of temperature and RH at the SPC station. However, model estimation may have significant deviation from the observations mainly due to the low $(191 \times 191 \mathrm{~km})$ resolution of the model. The temperature at the station at 10:00 UTC was higher for event days in all the seasons but in summer, when no significant difference between event and nonevent days was observed (Hamed et al., 2007). The RH at the station was much lower during event days in all the
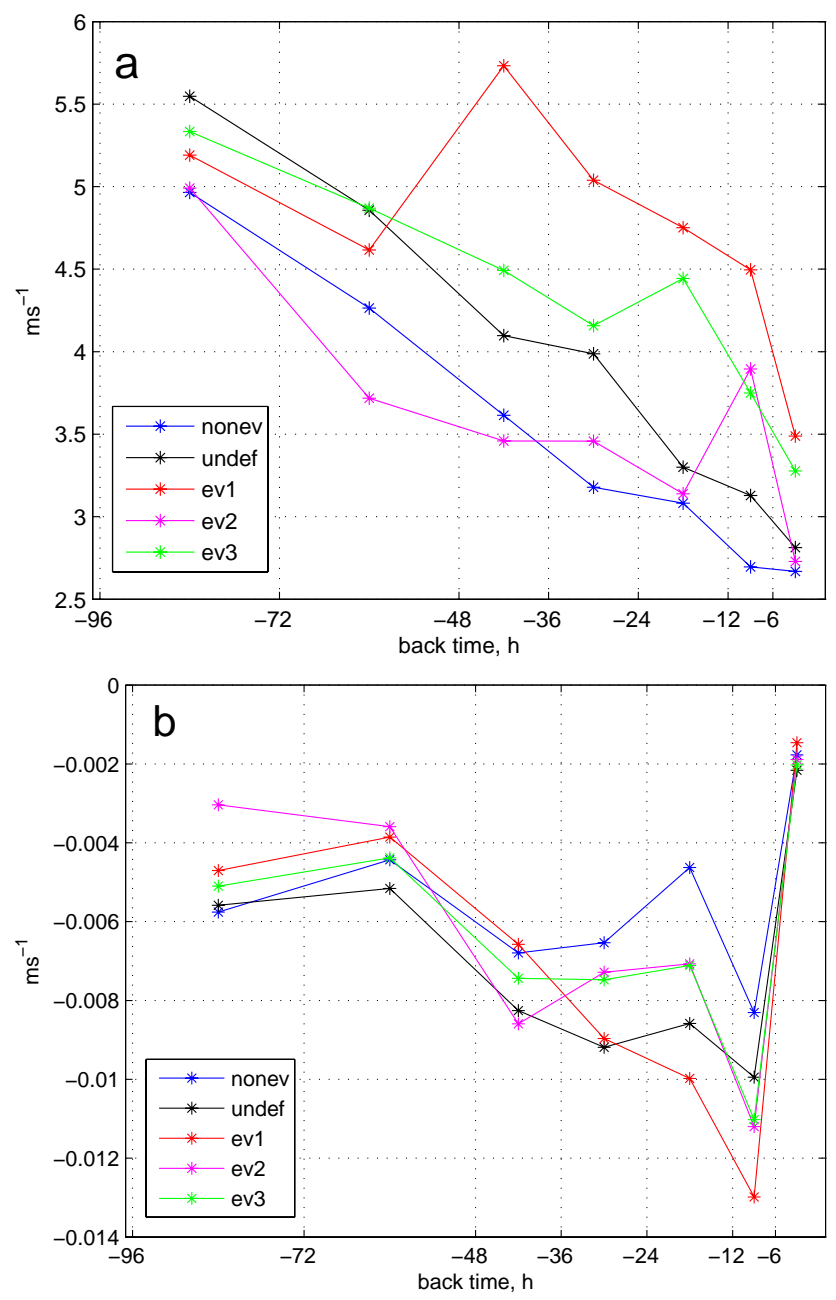

Fig. 5. Median horizontal (a) and vertical (b) velocity of air parcel averaged for different parts of trajectory $(96-72-48-36-24-$ $12-6-0 \mathrm{~h}$ back) for different group of days (blue line - nonevent days, black line - undefined days, red line - event class 1 days, magenta - event class 2 days, green - event class 3 days). The points are connected for clarity.

seasons but in summer, when the difference between event and nonevent days was much smaller. The same tendency is clearly seen in Fig. 4c.

The rain conditions leading to washout of water-soluble gases and aerosols (Flossmann, 1985) are presented in Fig. 4f. Precipitation occurred more often along the event trajectories, whereas during the last $12 \mathrm{~h}$ of the path the precipitation along the event trajectories except for autumn was close to 0 (not shown here). More intensive precipitation along the event trajectories implies the role of the wet deposition in the reduction of the condensation sink prior to particle formation event (Hamed et al., 2007). Thus, the meteorological conditions along the air parcel trajectory differ considerably during approximately two days before the arrival. 


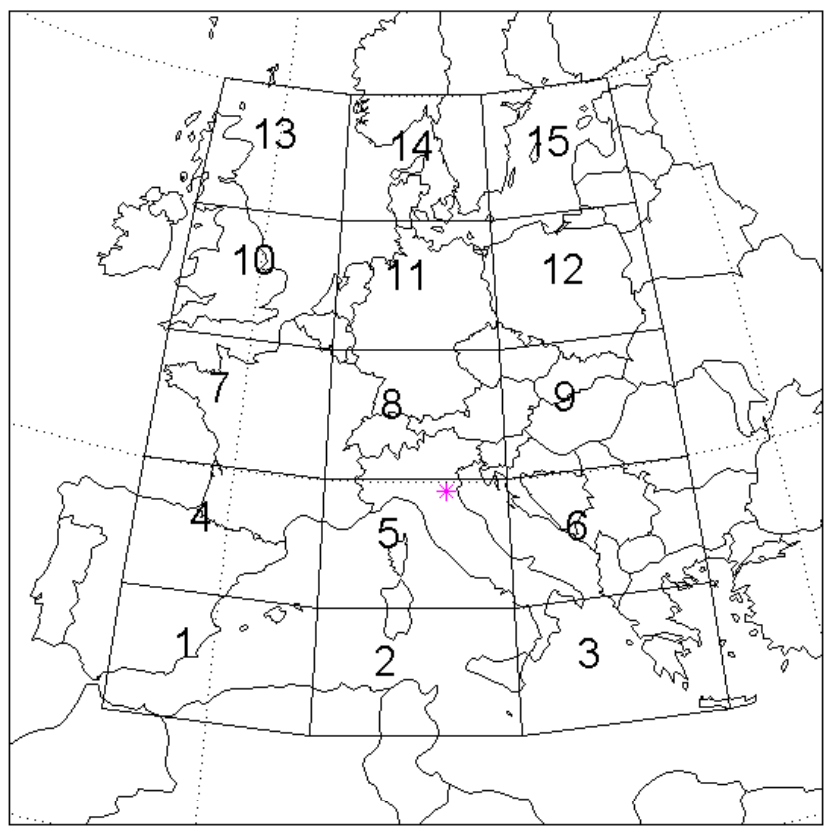

Fig. 6. Schematic figure of the sub-areas used in the probability analysis.

The difference between air mass properties along event and nonevent trajectories, which can be explained by the distinction in air parcel subsidence rate, becomes more significant during the last $12 \mathrm{~h}$ before the air parcel arrives at the measurement station. The subsidence causes sharp temperature increase and RH decrease.

Having found the difference in travelled distance and in subsidence height between event and nonevent trajectories, we calculated the median horizontal and vertical velocities of air parcels for event classes 1 to 3, nonevent and undefined days trajectories to estimate if there is any dependence between intensity of particle formation and the velocity of air parcel, which indicates how fast the air parcel properties may change along the trajectory.

Median horizontal velocity (Fig. 5a) decreases in the direction to the recipient from the origin point of the trajectory to the recipient.The decreasing of the horizontal velocity is due to the increasing of surface roughness and friction velocity in the direction from the Atlantic and northern Europe to the central part of Europe, which is the most favourable air mass transport direction. However, the horizontal velocity for event class 1 days increases from $4.6 \mathrm{~m} / \mathrm{s}$ in time sector $72-48 \mathrm{~h}$ before the arrival to $5.7 \mathrm{~m} / \mathrm{s}$ in time sector $48-36 \mathrm{~h}$ before the arrival. During the last day before the arrival the increasing of horizontal velocity is also observed for event classes 2 and 3 trajectories, while air parcel velocity decreases monotonously along the nonevent and undefined trajectories.

Median vertical velocity (Fig. 5b) does not change a lot for the period between 96 and $48 \mathrm{~h}$, but increases sharply dur- ing the last 48 to $6 \mathrm{~h}$ before the arrival due to the air parcel subsidence. The strongest vertical velocity $(-0.013 \mathrm{~m} / \mathrm{s}$ on average) is observed in event class 1 trajectories in a time period of 12-6h. Event class 2 and 3 trajectories also show higher values in this time period than undefined and nonevent trajectories.

\section{Probability of aerosol particle formation events}

The analysis of the nucleation event probability at SPC as a function of the air mass origin ( $48 \mathrm{~h}$ before arrival to the recipient) and history was done for the area limited by $35^{\circ} \mathrm{N}$ and $60^{\circ} \mathrm{N}$ in latitude and $5^{\circ} \mathrm{W}$ and $25^{\circ} \mathrm{E}$ in longitude. This area was divided into 15 sub-areas of $10^{\circ} \times 5^{\circ}$ in longitudinal and latitudinal direction, respectively (Fig. 6). We considered that the accuracy of the trajectory calculations is within the size of the sub-area. Such a division allows us to estimate the influences of small scale regions traversed by the air masses on nucleation events at SPC, and to make a conclusions on synoptic scale regions impact (Central Europe, Eastern Europe and Atlantic)on aerosol particle formation.

In the present investigation the air parcel passing over several sub-areas $(s)$ were registered in each sub-area through which the trajectory passed. However the contribution of the sub-area into air mass properties depends on how long the air parcel travelled over the corresponding area. In Sogacheva et al. (2005a), each passage of a trajectory through a given subarea was registered with equal weight. Here we improve this calculation by weighting a trajectory passage through a subarea with the trajectory residence time $\left(\tau_{e v, s}\right.$ and $\left.\tau_{n e v, s}\right)$, which provides an indication of the fractional time spent inside a specific sub-area relative to total time spent inside the domain by air parcels for combined event classes 1 and 2 $\left(e v_{s}\right)$ and for nonevent $\left(n e v_{s}\right)$ trajectories, respectively:

$e v_{s}=\sum_{1}^{e} \frac{1}{\tau_{e v, s}}$

$n e v_{s}=\sum_{1}^{n e} \frac{1}{\tau_{n e v, s}}$

where $e, n e-$ are numbers of event and nonevent trajectories for sub-area $s$, respectively.

For each sub-area the probability $P_{S}$ of the event trajectories as a function of event and nonevent trajectories was calculated as:

$P_{s}=\frac{e v_{s}}{e v_{s}+n e v_{s}}$.

The probability of the particle formation events as a function of the origin and history of the air masses arrived at SPC is shown in Fig. 7. The numbers inside sectors indicate the total number of event and nonevent trajectories, passed over the corresponding sub-area. The number in sector 5 is the total number of event class 1 and 2 and nonevent 


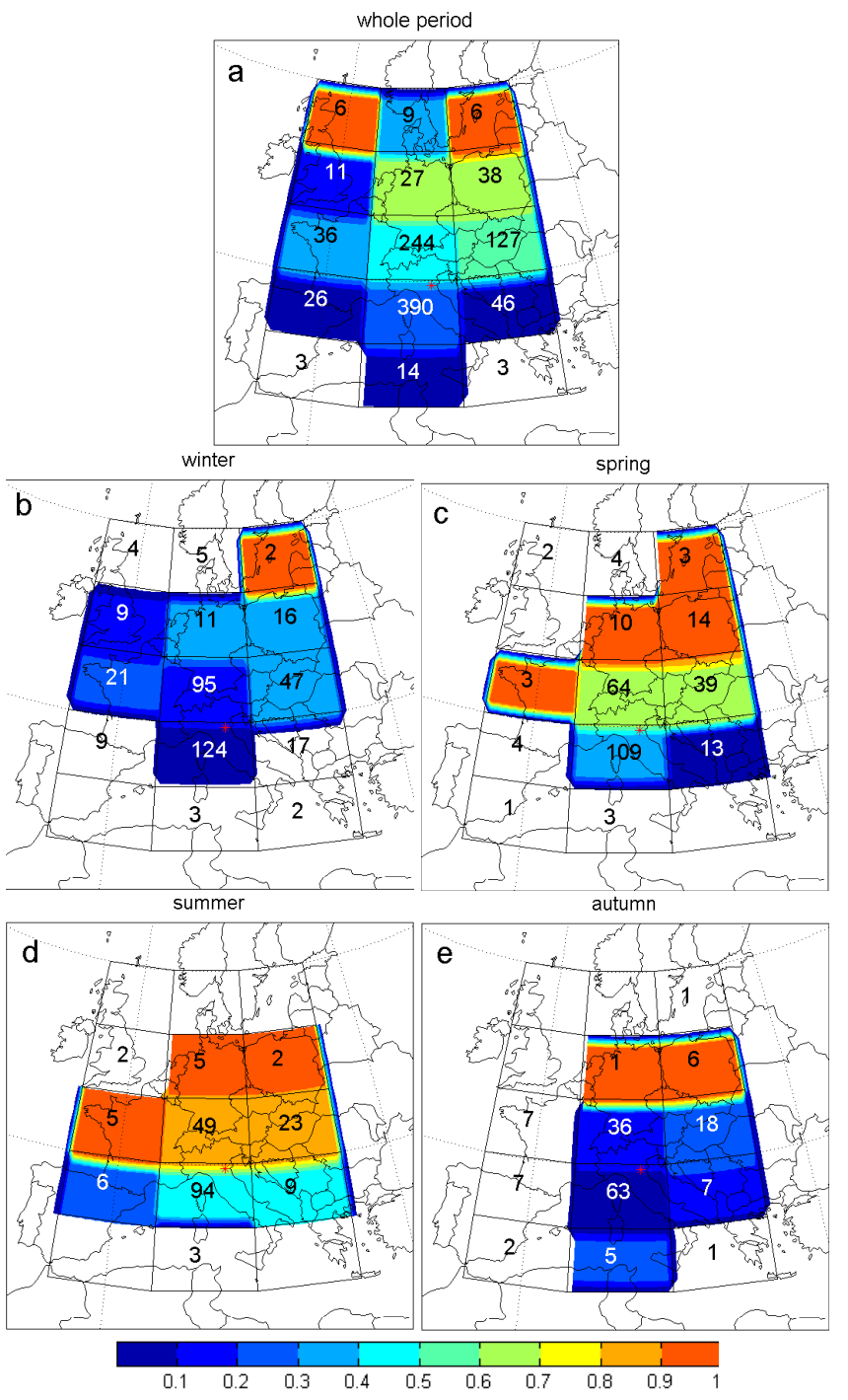

Fig. 7. Probability of nucleation events. Trajectories are normalized by the residence time in each sub-area. Number in sub-area is the number of event and nonevent trajectories, passed over that sub-area.

trajectories, arrived at SPC. On seasonal average (Fig. 7a) the highest (more than 0.9 ) probability of new particle formation events at the measurement station was observed in northern atmospheric flow, in air masses originated over the North Sea and Baltic Sea regions (sub-areas 13 and 15, respectively). A high probability (more than 0.6 ) is observed in the air masses originated and passed over north and northeastern Europe, i.e. over regions with large amount of anthropogenic sources of gaseous pollutants. In these areas the contribution of the particles directly emitted by the combustion processes and produced by the photochemical reactions is very important (Bowman et al., 1995). The lowest probability of nucleation events (less than 0.1) is observed in the air masses which reach SPC in other than northern atmospheric flows (sub-areas 1 to 4 and sub-area 6). However, southern transport of the air to SPC is observed seldom compared to other directions (Fig. 2). The northern atmospheric flow is the most favourable for new particle formation at SPC during all the seasons, though the portion of event trajectories in some sub-areas may change considerably from autumnwinter to spring-summer seasons.

In winter, when the monthly frequency of the nucleation events was the lowest compared to the other seasons (Hamed et al., 2007), the Baltic Sea was the single sub-area, for which the only event trajectories have been registered (Fig. 7b). The probability of event trajectories in the other northern subareas was very low (less than 0.4 ). No nucleation events have been observed at SPC during southern air mass transport in winter.

In spring (Fig. 7c) all the trajectories originating over the 


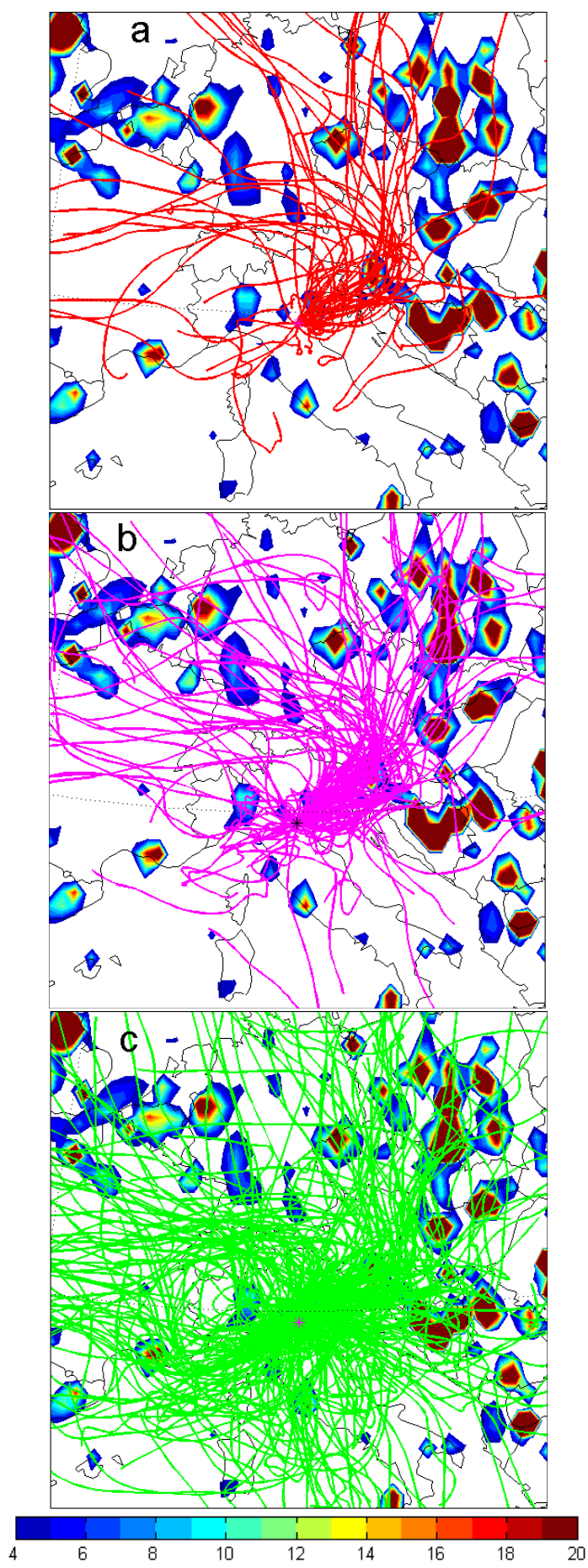

Fig. 8. $\mathrm{SO}_{2}$ emission sources (Tg year ${ }^{-1}$, EMEP data base) and event class 1 (a), event class 2 (b) and nonevent (c) trajectories for the whole period of measurements.

Baltic Sea, Poland, Germany and north-west Spain were event trajectories. The portion of event trajectories passed over central Europe was also high (more than 0.6). In summer (Fig. 7d) the probability distribution was close to that in spring, however the portion of the event trajectories passed over central Europe was higher (up to 0.9).

In autumn (Fig. 7e), when the aerosol instrument at SPC has malfunctioned the most (47\% operational days in autumn compared to $91 \%$ in winter, $76 \%$ in spring and $68 \%$ in summer), the probability of event trajectories in sub-areas 11 and 12 was the highest (equal to unity), whereas for the other sub-areas it was very low (less than 0.3 ). No event trajectories were observed in western air flow.

\section{Sulphur dioxide potential sources}

Hamed et al. (2007) reported that $\mathrm{SO}_{2}$ concentrations observed were higher on event days comparing with nonevent days. As sulphuric acid has been suggested to be the key species causing nucleation events (e.g. Kulmala et al., 2000, 2006), we decided to investigate the location of the distant and local emission sources which may contribute to particle formation at SPC. Using back trajectories we aimed to estimate how big fraction of $\mathrm{SO}_{2}$ can be transported from European emission sources to SPC.

Sulphur dioxide, which is the predominant anthropogenic sulphur-containing air pollutant, is released to the atmosphere by various anthropogenic and natural sources, the major ones being fuel combustion, industrial processes, volcanoes, and dimethyl sulfate oxidation (Davidson et al., 1996). $\mathrm{SO}_{2}$ reacts under tropospheric conditions via both gas- and aqueous-phase processes and is also removed physically via dry and wet deposition by the uptake of aerosols and clouds. With respect to gas-phase reaction, oxidation of $\mathrm{SO}_{2}$ by $\mathrm{OH}$ radical is dominant (Stockwell and Calvert, 1983). The lifetime of $\mathrm{SO}_{2}$ based on the reaction with the $\mathrm{OH}$ radical, at typical atmospheric levels of $\mathrm{OH}$, is about 10 days, while in cloud-phase reactions lifetime decreases to as low as several hours (Porter et al., 2002).

The combination of mesoscale circulations and local emissions strongly influence the spatial distribution of $\mathrm{SO}_{2}$. As shown in Figs. 8 and 9, a large fraction of event trajectories before the arrival at SPC pass over Central Europe which remains a strong source of anthropogenic emissions. In our studies we focused on the estimation of how often the trajectories, divided to several groups according to the event classification (nonevent, classes 1 and 2), passed over the $\mathrm{SO}_{2}$ emission sources calculated by EMEP model (http://www.emep.int/).

In the Fig. 8 we present the $\mathrm{SO}_{2}$ emissions and the air parcel trajectories for event classes 1 and 2 (Figs. 8a and b, respectively) and nonevent days (Fig. 8c), observed at SPC. It is clearly seen that many of the event trajectories passed on their way to SPC the $\mathrm{SO}_{2}$ emission source over Slovenia, which has intensity more than $20 \mathrm{Tg}_{\text {year }}{ }^{-1}$ and $\mathrm{SO}_{2}$ emission source in Veneto(up to about $15 \mathrm{Tg}$ year $^{-1}$ ).

The mean frequency and the mean travel distance for event class 1 and 2 trajectories and nonevent trajectories are shown in Fig. 9. The big fraction of event trajectories arrive at SPC 


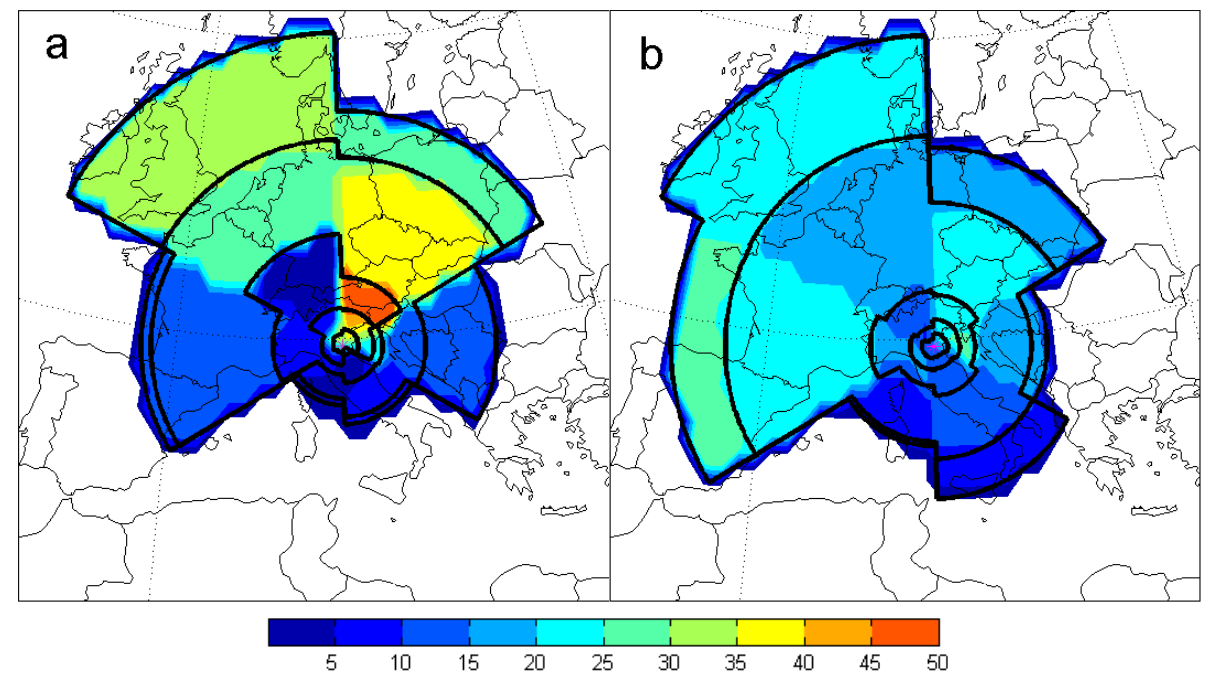

Fig. 9. Frequency (\%, color) of the location of an air parcel in different direction sectors between the reference back time steps (contour line for $-12 \mathrm{~h},-24 \mathrm{~h},-48 \mathrm{~h},-72 \mathrm{~h},-96 \mathrm{~h}$ ) for event (a) and nonevent (b) for the whole period of measurements.

from north-east direction, passing over Poland, Slovakia, Check Republic, eastern part of Germany about three to four days before the arrival, and passing over Slovenia at about one to two days before the arrival (Fig. 9a). The distribution of nonevent trajectories on the directions limited by $60^{\circ} \mathrm{sec}-$ tors is more uniform (Fig. 9b). The fraction of north-eastern nonevent trajectories is less compared to event trajectories, whereas the fraction of western trajectories, which identify the transport of air masses from Atlantic over France, increases.

In order to investigate $\mathrm{SO}_{2}$ transport to SPC, we calculated the potential (cumulative) $\mathrm{SO}_{2}$ concentration along the trajectory for periods when the air parcel was within the mixed layer (Hysplit_4 output) from the EMEP $\mathrm{SO}_{2}$ sources. For each $0.5^{\circ} \times 0.5^{\circ}$ grid area $i$, travelled by the air parcel, $\mathrm{SO}_{2}$ emission flux $\left(\mathrm{Mg}\right.$ year ${ }^{-1}$ ) was converted to $\mathrm{SO}_{2}$ concentration $c_{i}\left(\mu \mathrm{g} \mathrm{m}^{-3}\right)$, taking into account the residence time of the air parcel in the corresponded grid area and mixed layer depth. To get the air parcel residence time in a $0.5^{\circ} \times 0.5^{\circ}$ grid area we interpolated the trajectory 1 -hour back points to $0.5^{\circ} \times 0.5^{\circ}$ grid, corresponding to the EMEP emission data base.

The cumulative $\mathrm{SO}_{2}$ concentration $C_{\text {cum }}$ was calculated as a sum of $c_{i}$ concentrations over $i$ areas, travelled by the air parcel during time $t_{i}$. The effect of $\mathrm{SO}_{2}$ removal from the air parcel on $C_{\text {cum }}$ was taken into account using the parameter $\tau$, which is considered being an analog to $\mathrm{SO}_{2}$ lifetime. Thus,

$C_{\text {cum }}=\sum_{1}^{i} c_{i} \cdot \exp \frac{-t_{i}}{\tau}$.

In the initial calculations $\tau$ was considered as a lifetime with respect to dry and wet deposition processes (10 days and 1.8

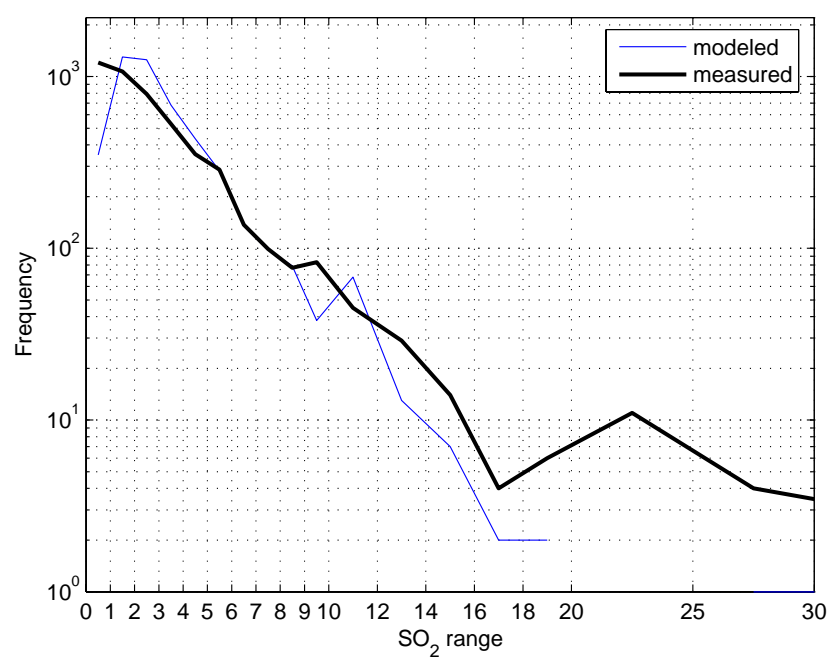

Fig. 10. Modeled (blue line), using EMEP emission data and air masses back trajectories $(\tau=24 \mathrm{~h})$ and measured (black line) $\mathrm{SO}_{2}$ concentration, $\left(\mu \mathrm{g} \mathrm{m}^{-3}\right)$.

days, respectively), but because other processes, which may influence $\mathrm{SO}_{2}$ concentration (especially dilution due to mixing with cleaner air) were not taken into account, $C_{\text {cum }}$ concentration deviated from measured $\mathrm{SO}_{2}$ values considerably. To improve the agreement we decided to treat $\tau$ as an adjustable parameter, describing the effective decay timescale of $\mathrm{SO}_{2}$ in the air parcel, in order to find the best fit of $C_{\text {cum }}$ to $\mathrm{SO}_{2}$ concentration value measured at the station.

As expected, the correlation between modeled and measured $\mathrm{SO}_{2}$ concentrations was low at all values of $\tau$. Reasons for this include the annual averaging of EMEP data, which conceals the well defined seasonal cycle with a win- 

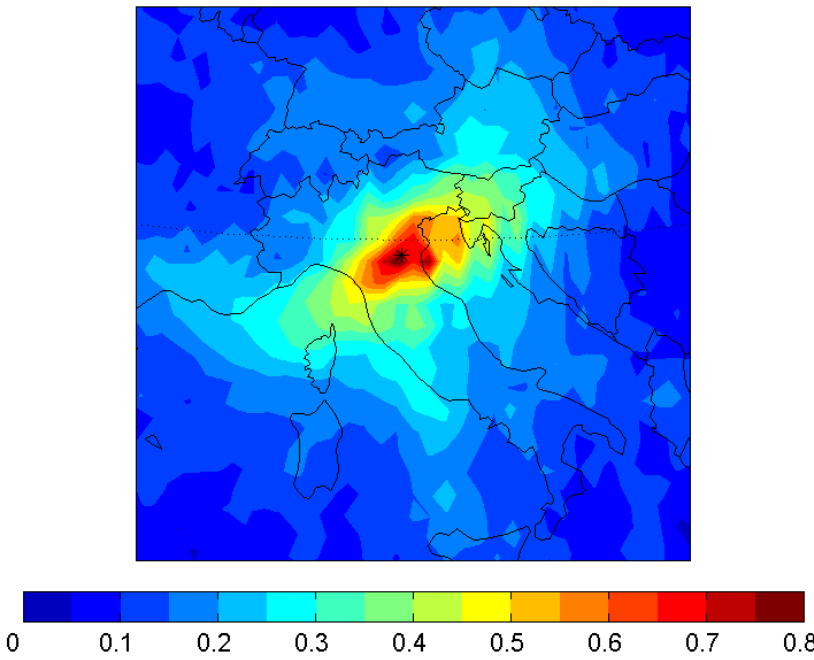

Fig. 11. The fraction of the $\mathrm{SO}_{2}$ concentration (\%) transported to SPC (modeled using back trajectories and EMEP emission data).

ter maximum and summer minimum. Moreover, the accuracy of the trajectory analysis decreases in case of difficult meteorological conditions and over the complex terrain, as discussed above. It should also be kept in mind that $\tau$ is a parameter that describes removal and dilution processes in an averaged and simplified manner. Thus, rather than trying to determine $\tau$ based on direct correlations, we looked for the $\tau$ value that best reproduces the statistical frequency distribution of the measured $\mathrm{SO}_{2}$ concentrations. The best agreement was found with $\tau=24 \mathrm{~h}$. As shown in Fig. 10, the modeled and measured distributions are reasonably similar for the most part. The measured distribution shows a tail of very high $\mathrm{SO}_{2}$ values absent from the modeled distribution. One possible explanation for these high values are instances when the measurement station is influenced by a plume from a local strong emission source directly upwind (Wang et al., 2006). In any case, only a small minority of measured $\mathrm{SO}_{2}$ values represents high concentrations larger than about $15 \mu \mathrm{g} \mathrm{m}^{-3}$, and we therefore believe that our simple transport modelling with $\tau=24 \mathrm{~h}$ reproduces the measured $\mathrm{SO}_{2}$ concentration range reasonably well.

Chin et al. (2000a) reported that in global models of atmospheric sulfur cycle simulation $\mathrm{SO}_{2}$ lifetime is taken in the size range of 1.8 to 2.6 days that is about 2 to 2.5 times higher compared to the parameter $\tau$ in our calculations. However, the model agrees within $30 \%$ with the regionally averaged sulfate concentration measured over North America and Europe but overestimates the $\mathrm{SO}_{2}$ concentrations by more than a factor of 2 there (Chin et al., 2000b).

We also estimated how much of $\mathrm{SO}_{2}$ can be transported to the recipient when $\tau=24 \mathrm{~h}$. For each trajectory $j$ we considered the travelled $0.5 \times 0.5^{\circ}$ area $i$ with concentration $c_{0, i, j}$, and calculated $c_{r, i, j}$, the concentration that remains in the at-
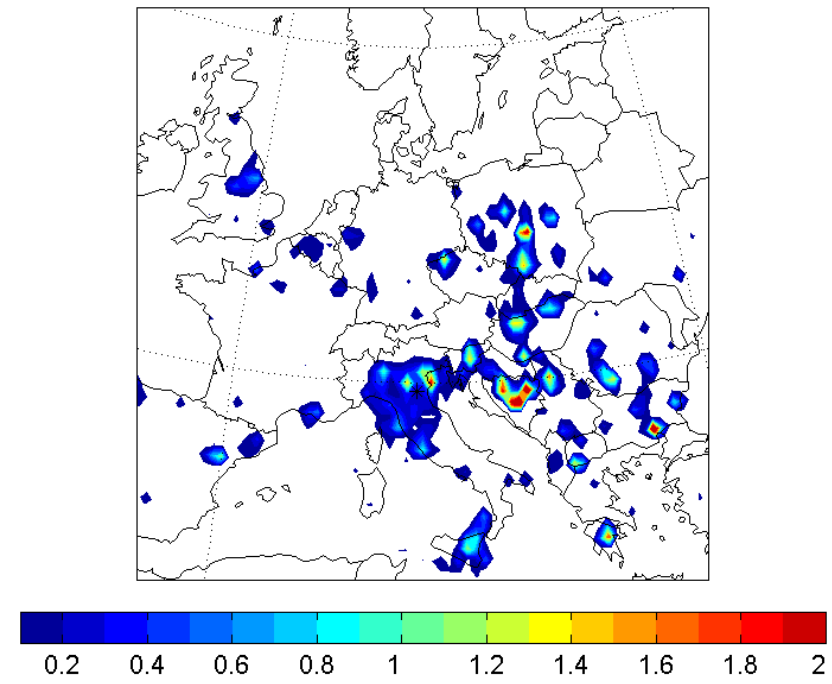

Fig. 12. The contribution of the $\mathrm{SO}_{2}$ emission sources $\left(\mu \mathrm{g} \mathrm{m}^{-3}\right)$ to $\mathrm{SO}_{2}$ concentration at SPC (modeled using back trajectories and EMEP emission data).

mosphere after time $t_{i, j}$

$c_{r, i, j}=c_{0, i, j} \times \exp \left(\frac{-t_{i, j}}{24}\right)$,

where $t_{i, j}$ is the travel time of the air parcel $j$ from the source area $i$ to the recipient.

Afterwards we calculated $c \%, i, j$, the fraction of the transported concentration to the concentration over the area $i$

$c \%, i, j=\frac{c_{r, i, j}}{c_{0, i, j}}$.

For each area $i$ we calculated $c \%, i$, the mean fraction of the concentration, transported from the area to the recipient

$c \%, i=\frac{\sum_{1}^{j} c \%, i, j}{j}$.

The preliminary analysis of the contribution of different $\mathrm{SO}_{2}$ source areas to the concentration at SPC (Fig. 11) shows that more than $40 \%$ of the emissions over the Po Valley reach $\mathrm{SPC}$, whereas the fraction of European $\mathrm{SO}_{2}$ emissions that can be observed at SPC is $10 \%$ to $30 \%$ on average. This means that the less distant $\mathrm{SO}_{2}$ source regions seem to be more important for the $\mathrm{SO}_{2}$ concentration measured at SPC than the emission sources in the Central Europe. Also the increase (decrease) of $\mathrm{SO}_{2}$ emissions in Po Valley will change the concentration at the station considerably compared to the $\mathrm{SO}_{2}$ emission changes over Europe.

However, the real contribution depends not only on how big fraction of the emission can be transported, but also on the initial concentration of $\mathrm{SO}_{2}$ in the source areas. Having estimated the mean concentration for $0.5 \times 0.5^{\circ}$ area from 
EMEP emissions fluxes data and mixing layer height (Hysplit_4 output for the trajectories), we calculated how much of $\mathrm{SO}_{2}$ can be transported on average to the SPC from different areas. The results (Fig. 12) show, that even if the fraction of $\mathrm{SO}_{2}$ transported from the Central and Eastern Europe is less than 20\% (Fig. 11), the contribution of strong emission sources nevertheless remains noticeable (up to more than $2 \mu \mathrm{g} \mathrm{m}^{-3}$ from $0.5 \times 0.5^{\circ}$ area).

\section{Conclusions}

Air parcel trajectories have been analyzed to investigate the history of air masses and possible link between the air masses history and new particle formation events at San Pietro Capofiume measurement station, Po Valley, Italy. By means of trajectory analysis the $\mathrm{SO}_{2}$ emission sources in $\mathrm{Eu}$ rope have been estimated as a potential sources influencing $\mathrm{SO}_{2}$ concentration at SPC.

Westerly to north-easterly air mass transport occurs more frequently in all the seasons at SPC. Due to the low pressure zone activity, horizontal transport is much stronger in winter compared to summer. The velocity of an air parcel decreases towards the arrival point due to the increasing influence of the surface roughness.

With rare exception, mixed layer depth is higher along the event trajectories. However, such parameters as temperature and relative humidity, which along with origin are determined by the elevation of the air parcel, have a reversal differences between event and nonevent trajectories. We found that, on average, event trajectories undergo stronger subsidence than nonevent trajectories during the last $12 \mathrm{~h}$ before the arrival at SPC; the amplitude of the increasing of the vertical velocity for event class 1 trajectories is the highest. Higher temperature, lower rain, relative and absolute humidity are also typical for event trajectories.

Nucleation events occur more frequently in air masses arriving from Central Europe, whereas event frequency is much lower in the air masses transported from both southern directions and the Atlantic Ocean.

The $\mathrm{SO}_{2}$ emission sources in Europe have been considered as potential sources influencing $\mathrm{SO}_{2}$ concentration at SPC. Air masses trajectories often pass over the polluted $\left(\mathrm{SO}_{2}\right)$ Slovenia region and over the Veneto emission sources, east from the station. Po Valley $\mathrm{SO}_{2}$ source regions seem to be more important in its contribution to the concentration at SPC than the emission sources in the Central Europe. However, the contribution of strong emission sources over the Central and Eastern Europe nevertheless is substantial.

\section{References}

Ansmann, A., Bösenberg, J., Chaikovsky, A., Comerón, A., Eckhard, S., Eixman, R., Freudenthaler, V., Ginoux, P., Komguem, L., Linné, H., Márquez, M. Á., Mattis, I., Mitev, V., Müller, D., Music, S., Nickovic, S., Pelon, J., Sauvaeg, L., Sobolevsky, P., Srivastsva, M. K., Stohl, A., Torre, O., Vaughan, G.,
Wandinger, U., and Wiegner, M.: Long-range transport of Saharan dust to northern Europe: The 1-16 October 2001 outbreak observed with EARLINET, J. Geophys. Res., 108, 4782, doi:10.1029/2003JD003757, 2003.

Balkanski, Y., Bauer, S. E., van Dingenen, R., Bonasoni, P., Shultz, M., Fisher, H., Gobbi, G. P., Hanke, M., Hauglustain, D., Putaud, J. P., Stohl, A., and Raes, F.: The Mt. Cimone, Italy, free Tropospheric campaign: principal characteristics of the gaseous and aerosol composition from European pollutions, Mediterranean influence and during African dust events, Atmos. Chem. Phys. Discuss., 3, 1753-1776, 2003, http://www.atmos-chem-physdiscuss.net/3/1753/2003/.

Bertò, A., Buzzi, A., and Zardi, D.: Back-tracking water vapour contributing to a precipitation event over Trentino: a case study, Meteorologische Zeitschrift, 13(3), 189-200, 2004.

Bonasoni, P., Stohl, A., Cristofanelli, P., Calzolari, F., Colombo, T., and Evangelisti, F.: Background ozone variations at Mt. Cimone station, Atmos. Environ., 34, 5183-5189, 2000.

Bonasoni, P., Cristofanelli, P., Calzolari, F., Bonafè, U., Evangelisti, F., Stohl, A., Zauli Sajani, S., van Dingenen, R., Colombo, T., and Balkanski, Y.: Aerosol-ozone correlation during dust transport episode, Atmos. Chem. Phys., 4, 1201-1215, 2004, http://www.atmos-chem-phys.net/4/1201/2004/.

Bowman, F. M., Pilinis, C., and Seinfeld, J. H.: Ozone and aerosol productivity of reactive organics, Atmos. Environ., 29, 579-589, 1995.

Boy, M., and Kulmala, M.: Nucleation events in the continental boundary layer: Influence of physical and meteorological parameters, Atmos. Chem. Phys., 2, 1-16, 2002, http://www.atmoschem-phys.net/2/1/2002/.

Chin, M., Rood, R. B., Lin, S.-J., Müller, J.-F., and Thompson, A. M.: Atmospheric sulfur cycle simulated in the global model GOCART: Model description and global properties, J. Geophys. Res., 105(D20), 24 671-24 687, 2000a.

Chin, M., Savoie, D. L., Huebert, B. J., Bandy, A. R., Thronton, D. C., Bates, T. S., Quinn, P. K., Saltzman, S. C., and De Bruyn, W. J.: Atmospheric sulfur cycle simulated in the global model GOCART: Comparison with field observation and regional budgets, J. Geophys. Res., 105(D20), 24 689-24 712, 2000 b.

Davidson, B., O’Dowd, C., Hewitt, C. N., Smith, M. H., Harrison, R. M., Peel, D. A., Wolf, E., Mulvaney, R., Schwikowsky, M., and Baltensperger, U.: Diethyl sulfide and its oxidation products in atmosphere of Atlantic and Southern oceans, Atmos. Environ., 30, 1895-1906, 1996.

Draxler, R. and Hess, G. D.: An overview of the HYSPLIT_4 modeling system for trajectories, dispersion and deposition, Australian Meteorological Magazine, 47, 295-308, 1998.

Draxler R. R. and Hess, G. D.: Description of the HYSPLIT_4 Modeling System, NOAA Technical Memorandum ERL ARL-224, 2004.

Finardi, S. and Pellegrini, U.: Systematic analysis of meteorological conditions causing severe urban air pollution episodes in the central Po Valley, 9t Int. Conf. on Harmonization within Atmospheric Dispersion Modeling for Regulatory Purposes, 250-254, 2004.

Flossmann, A. I.: A theoretical study of the wet removal of atmospheric pollutants. Part I: the redistribution of aerosol particles captured through nucleation and impaction scavenging by growing cloud drops, J. Atmos. Sci., 42, 583-606, 1985. 
Hamed, A., Joutsensaari, J., Mikkonen, S., Sogacheva, L., Dal Maso, M., Kulmala, M., Cavali, F., Facchini, M. C., Decesari, S., Mircea, M., Lehtinen, K. E. J., and Laaksonen, A.: Nucleation and growth of new particles in Po-Valley, Italy, Atmos. Chem. Phys., 7, 335-376, 2007, http://www.atmos-chemphys.net/7/335/2007/.

Hellmuth, O.: Columnar modelling of nucleation burst evolution in the convective boundary layer - first results from a feasibility study Part III: Preliminary results on physicochemical model performance using two clean air mass" reference scenarios, Atmos. Chem. Phys., 6., 4231-4251, 2006

Hyvönen, S., Junninen, H., Laakso, L., Dal Maso, M., Grönholm, T., Bonn, B., Kerronen, P., Aalto, P., Hiltunen, V., Pohja, T., Launiainen, S., Hari, P., Mannila, H., and Kulmala, M.: A look at aerosol formation using data mining techniques, Atmos. Chem. Phys., 5, 3345-3356, 2005, http://www.atmos-chemphys.net/5/3345/2005/.

Kruger, B. C., Kroger, H., Wotawa, G., and Kromp-Kolb, H.: Lagrangian Photochemical Model calculations for the Milan area, in: Proc. EURTRAC-2 Symposium 2000, edited by: Midgley, P. M., Reuther, M., and Williams, M., Springer Verlag, Berlin, 2000.

Kulmala, M., Rannik, Ü., Pirjola, L., Dal Maso, M., Karimäki, J., Asmi, A., Jäppinen, A., Karhu, V., Korhonen, H., Malvikko, S.P., Puustinen, A., Raittila, J., Rommakaniemi, S., Suni, T., Yli Koivisto, S., Paatero, J., Hari, P., and Vesala, T.: Characterization of atmospheric trace gas and aerosol concentrations at forest sites in southern and northern Finland using back trajectories, Boreal Environ. Res., 5, 315-336, 2000.

Kulmala, M., Dal Maso, M., Mäkelä, J. M., Pirjola, L., Väkevä, M., Aalto, P., Miikkulainen, P., Hämmeri, K., and O'Dowd, C.: On the formation, growth and composition of nucleation mode particles, Tellus 53B, 479-490, 2001.

Kulmala, M.: How particles nucleate and grow, Science, 302(7), 1000-1001, 2003.

Kulmala, M., Vehkamäki, H., Petäjä, T., Dal Maso, M., Lauri, A., Kerminen, V.-M., Birmili, W., and McMurry, P.: Formation and growth rates of ultrafine atmospheric particles: a review of observations, J. Aerosol Sci., 35, 143-176, 2004.

Kulmala, M., Lehtinen, K. E. J., and Laaksonen, A.: Cluster activation theory as an explanation of the linear dependence between formation rate of $3 \mathrm{~nm}$ particles and sulphuric acid concentration, Atmos. Chem. Phys., 6, 787-793, 2006, http://www.atmoschem-phys.net/6/787/2006/.

Laaksonen, A., Hamed, A., Joutsensaari, J., Hiltunen, L., Cavalli, F., Junkermann, W., Asmi, A., Fuzzi, S., and Facchini, M. C.: Cloud condensation nucleus production from nucleation events at a highly polluted region, Geophys. Res. Lett., 32, L06812, doi:10.1029/2004GL022092, 2005.

Millan, M. (Ed.): Ozone dynamics in the Mediterranean basin, Air Pollution Research Report 78, Collection of scientific papers resulting from MECAPIP, RECAPMA, and SECAP projects. European Commission and CEAM, La ImprentaComunication Grafica, Spain, 2002.

Nilsson, E. D., Rannik Ü., Kulmala, M., Buzorius, G. and O’Dowd., C. D. : Effects of continental boundary layer evolution, convection, turbulence and entrainment, on aerosol formation, Tellus, 53B, 441-446, 2001.

O’Dowd, C. D., Smith, M. H., Consterdine, I. E., and Lowe, J. A.:
Marine aerosol, sea-salt, and the marine sulphur cycle: a short review, Atmos. Environ., 31, 73-80, 1997.

O’Dowd, C. D., Facchini, M. C., Cavalli, F., Ceburnis, D., Mircea, M., Decesari, S., Fyzzi, S., Yoon, Y. J., and Putaud, J.-P.: Biogenically driven organic contribution to marine aerosol, Nature, 431, 676-680, 2004.

Pichlmayer, F., Schöner, W., Siebert, P., Stichler, W., and Wagenbach, D.: Stable isitipe analysis fro characterization of pollutants at high elevation Alpine sites, Atmos. Environ., 32, 4075-4085, 1998.

Porter, J., Horton, K. A., Mouginis-Mark, P. J., Linert, B., Lau, E., Sutton, J., Elias, T., and Oppenheimer, C.: Sun photometer and lidar measurements of the plume from the Hawaii Kilauea Volcano Pu'u 'O'o vent: Estimates of aerosol flux rates and $\mathrm{SO}_{2}$ life time, Geophys. Res. Lett., 29, 16, doi:10.1029/2002GL014744, 2002.

Putaud, J.-P., Van Dingenen., R., Dell'Acqua, A., Raes, F., Matta, E., Decesari, S., Facchini, M. S., and Fuzzi, S.: Size-segregated aerosol mass closure and chemical composition in Monte $\mathrm{Ci}$ mone (I) during MINATROC, Atmos. Chem. Phys., 4, 889-902, 2004, http://www.atmos-chem-phys.net/4/889/2004/.

Siebert, P., Kromp-Kolb, H., Kasper A., Kalina, M., Puxbaum, H., Jost, D. T., Schwikowski, M., and Baltensperger, U.: Transport of polluted boundary layer air from the Po valley to high alpine sites, Atmos. Environ., 32, 3953-3965, 1998.

Sogacheva, L., Dal Maso, M., Kerminen, V.-M., and Kulmala, M.: Probability of nucleation events and aerosol particle concentration in different air mass types arriving at Hyytiälä, southern Finland, based on back trajectory analysis, Boreal Environ. Res., 10, 479-491, 2005a.

Sogacheva, L., Dal Maso, M. and Kulmala, M.: Aerosol particle number concentration and condensation sink study at Hyytiälä, southern Finland, using back trajectory analysis, Second Joint BACCI Meeting, Kuopio, Finland, 102-105, 2005 b.

Steinbacher, M., Dommen, J., Ordonez, C., Reimann, S., Grüebler, F. C., Staehelin, J., and Prevot, A. S. H.: Volatile organic compounds in the Po Basin. Part A: Anthropogenic VOC's, J. Atmos. Chem., 51, 271-291, 2005a.

Steinbacher, M., Dommen, J., Ordonez, C., Reimann, S., Grüebler, F. C., Staehelin, J., Andtreani-Aksoyoglu, S., and Prevot, A. S. H.: Volatile organic compounds in the Po Basin. Part B: Biogenic VOC's, J. Atmos. Chem., 51, 293-315, 2005b.

Stockwel, W. R. and Calvert, J. G.: The mechanism of the OH-SO reactions, Atmos. Environ., 17, 2231-2235, 1983.

Stohl, A., Wotava, G., Siebert, P., and Kromp-Kolb, H.: Interpolation errors in wind fields as a function of spatial and temporal resolution and their impact on different types of kinematic trajectories, J. Appl. Meteorol., 34, 2149-2165, 1995.

Stohl, A.: Computation, accuracy and applications of trajectories a review and bibliography, Atmos. Environ., 32, 947-966, 1998.

Van Dingenen, R., Putaud, J.-P., Martin-Dos Santos, S., and Raes, F.: Physical aerosol properties and their relation to air mass origin during the first MINATROC campaign, Atmos. Chem. Phys., 5, 2203-2226, 2005, http://www.atmos-chemphys.net/5/2203/2005/.

Vesala, T., Kulmala, M., Rudolf, R., Vrtala, A., and Wagner, P. E.: Models for condensational growth and evaporation of binary aerosol particles, J. Aerosol. Sci., 28(4), 565-598, 1997.

Wang, P., Richter, A., Bruns, M., Burrows, J. P., Scheele, R., Junker- 
mann, W., Heue, K.-P., Wagner, T., Platt, U., and Pundt, I.: Airbone multi-axis DOAS measurements of troposhperic SO2 plums in the Po-valley, Italy, Atmos. Chem. Phys., 6, 329-338, 2006, http://www.atmos-chem-phys.net/6/329/2006/.
Wotawa, G., Kröger, H., and Stohl, A.: Transport of ozone towards the Alps - results from trajectory analysis and photochemical model studies, Atmos. Environ., 34, 1367-1377, 2000. 